\section{HYPOPARATHYROIDISM AND PSEUDO-HYPOPARATHYROIDISM}

BY

R. R. de MOWBRAY, D.M., M.R.C.P.

Registrar, Endocrine Department, Guy's Hospital

\section{S. H. LLEWELLYN SMITH, B.M., M.R.C.P. Physician, Lewisham General Hospital}

AND

\section{W. J. C. SYMONDS, B.M., B.Ch. Medical Registrar, Guy's Hospital}

Hypoparathyroidism is well recognized as a complication of thyroidectomy. In most series of cases reported in the literature the incidence has been less than $1 \%$ after operations for hyperthyroidism, the figures ranging from $0.2 \%$ (Cattel, 1934) to $3.5 \%$ (Lachmann, 1941) ; in about half the cases the tetany is only transient. Idiopathic hypoparathyroidism is generally regarded as a rarity. Only 60 to 70 proved cases have been recorded in the literature, and only three of these have been reported from this country (Humphreys, 1939 ; Himsworth and Maizels, 1940 ; Jordan and Kelsall, 1951). Still rarer, perhaps, is the condition of pseudohypoparathyroidism, described by Albright et al. (1942), which results from abnormal resistance to parathyroid hormone rather than from deficient secretion. Only 18 cases have so far been reported.

We have been impressed by the variety of ways in which this group of disorders may present, and by the ease with which they may escape recognition. We believe that they may not be as rare as is commonly supposed. We therefore record three cases of idiopathic hypoparathyroidism, together with three illustrative cases of the post-operative condition and one case of pseudo-hypoparathyroidism. This last case has already been reported elsewhere (Bishop and de Mowbray, 1951), and is, so far as we are aware, the first to be recorded in this country.

\section{Case 1. Idiopathic Hypopara- thyroidism}

This patient, a man aged 44 , first noticed stiffness of his leg muscles after mild exercise when aged about 12 . At 22 he began to develop progressive failure of vision, at 40 a cataract was removed from his left eye. At the age of 32 he hegan to have carpopedal spasms, and between the attacks he had difficulty in moving his joints, owing to a feeling of "hardness" in the muscles. A few years later he developed sudden involuntary "flinging" movements of his limbs, occasionally causing him to fall to the ground. For four years he had difficulty in initiating sudden leg movements, on account of spasm of the muscles. For about 20 years his wife had noticed a gradual loss of his critical and introspective faculties, and, more recently, he himself had been aware of an impairment of his powers of concentration and emotional control. $\mathrm{He}$ had never had an operation on the thyroid gland. He had been treated for some years as a hysteric and later as an epileptic (one of his sisters had suffered from epilepsy in the past).

On examination he was facile and emotionally unstable, and liable to attacks of uncontrolled and sometimes inappropriate laughter. His powers of concentration were limited and variable, and intelligence tests showed deterioration (Wechsler Bellevue, 61 ; progressive matrix, Grade V). Chvostek's and Trousseau's signs were positive. A mature cataract was present in his right eye, and one had already been removed from his left eye. His skin and nails were normal, but his teeth were poor in quality.

Investigations.-The serum calcium was $6.5 \mathrm{mg}$., the phosphate $4.3 \mathrm{mg}$., and the alkaline phosphatase 18 units per $100 \mathrm{ml}$. The Sulkowitch test showed no calcium in the urine. The Ellsworth-Howard test gave a normal response to parathyroid hormone (Fig. 1). The faeces contained no excess of fat. $X$-ray films (Figs. 2 and 3 ) showed radiating striae of calcification in the caudate nucleus areas of the brain and possibly calcification in the cerebellum. Two of the last molar teeth were unerupted (Fig. 2). The pelvic bones showed increased density, with some calcification of the tendon insertions. The electroencephalogram
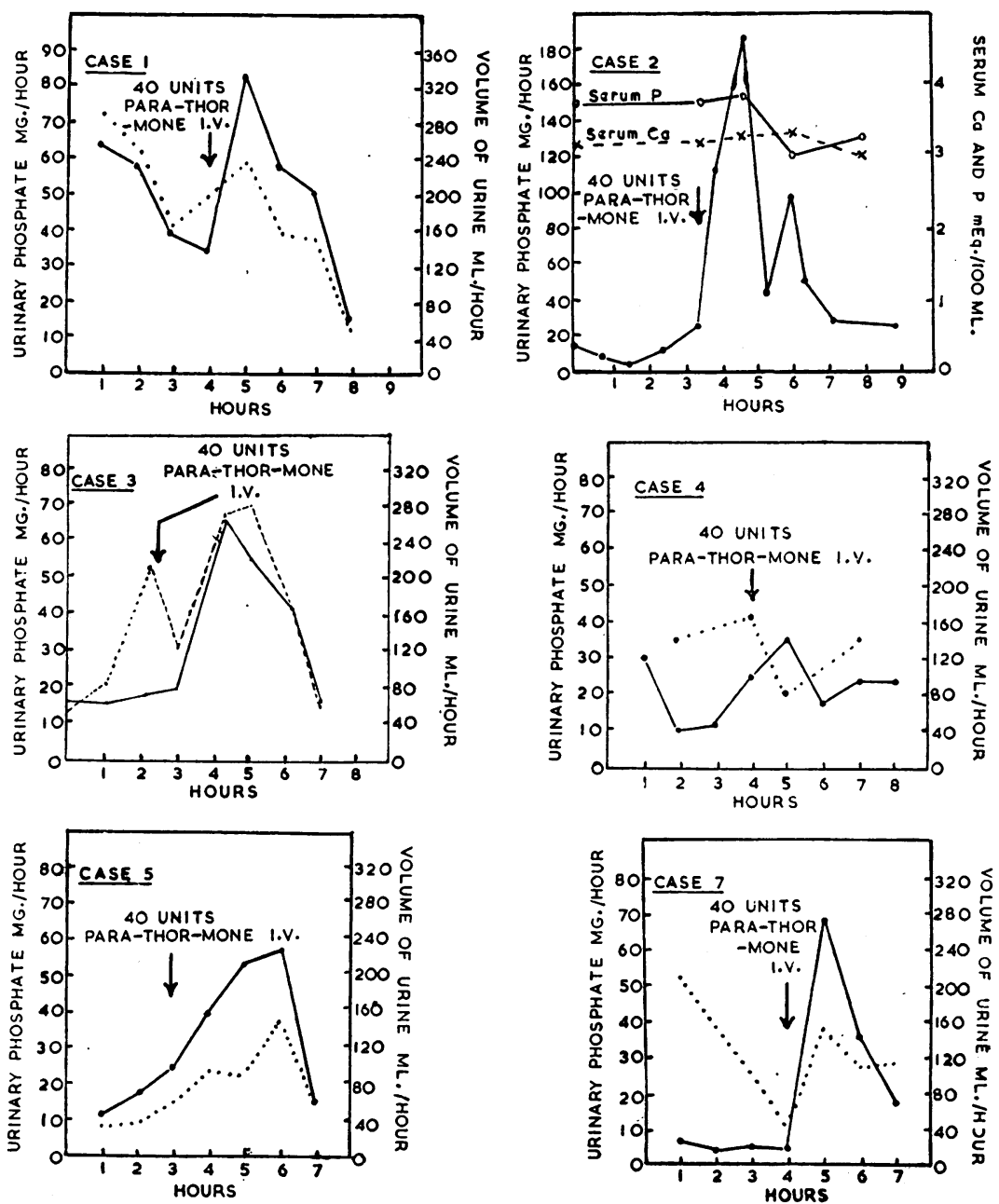

Fig. 1.-Ellsworth-Howard test. Administration of parathyroid hormone to subjects with true hypoparathyroidism (and to normal subjects) leads to a marked increase in urinary phosphate excretion and a water diuresis. There is no significant response in the case of pseudo-hypoparathyroidism. The patients were under basal conditions, except in Case $2 . \quad \underline{=}=$ Urinary phosphate level. $\ldots \ldots .=$ Urinary volume. 
showed abnormally slow dominant frequency at 6 to 7 cycles a second in the post-central areas. These waves were bilaterally symmetrical, and were inhibited by visual attention; hyperventilation led to a slight increase in dominant

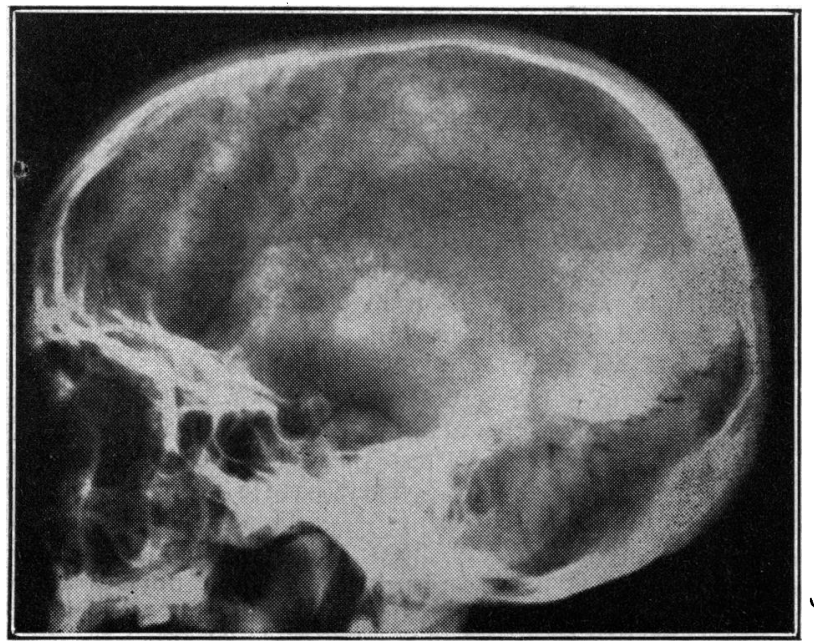

FIG. 2.-Case 1. Idiopathic hypoparathyroidism. Bilateral calcification in the basal ganglia, arranged in radiating striations. One of the unerupted molars is also shown.

frequency. The electrocardiogram showed low voltage in all leads, especially in the $T$ waves, and the $Q-T$ interval was prolonged.

Treatment.-Dihydrotachysterol, $1 \mathrm{ml}$. (1.25 mg.), was given three times daily, and the dose was gradually reduced

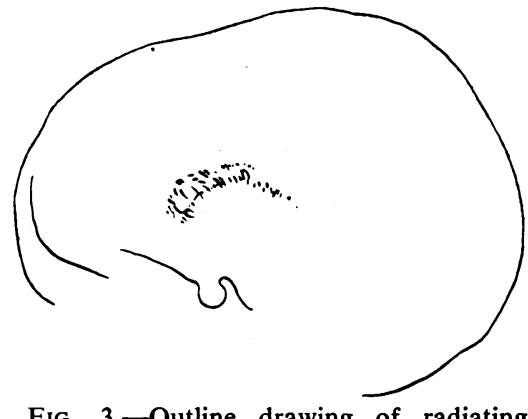

FIG. 3.-Outline drawing of radiating striae of calcification shown in Fig. 2. to a maintenance level of $1 \mathrm{ml}$. da i ly. La ten $\mathrm{t}$ tenany was abolished after five days, and the stiffness of the limbs disappeared. His mental state, however, remained unchanged. The cataract was successfully removed from his right eye. The e lectroencephalog r a m improved now showing a dominant alpha rhythm at 8 cycles a second, and the electrocardiogram returned to normal.

\section{Case 2. Idiopathic Hypoparathyroidism}

A man aged 41 was seen by an ophthalmic surgeon in February, 1951, on account of failing vision of three years' duration. He was found to have extensive bilateral posterior lamellar cataracts, and a reducing substance was present in the urine. He was therefore referred for a physician's opinion. On further questioning it was revealed that 12 years previously the hair of his head had fallen out rapidly in a patchy manner, and that it had never completely grown again. The eyebrows had also fallen out, and several of his nails had been shed and had only partially regrown. He had never had any symptoms of tetany, except for some paraesthesiae in the hands and a tendency to paraesthesiae and cramps in the legs. His wife said that for two or three years he had been becoming more morose, irritable, and forgetful, and had been losing interest in his appearance and cleanliness. He had never had an operation on the thyroid gland, and there was no relevant family history.

On examination the vertex of the scalp was almost completely bald, and at the sides of the head were patches of thinning, where the hairs were small, white, and brittle. Several of his nails had only partially grown again and were ridged, broken, and brittle (Fig. 4): scrapings from them failed to show any fungus. Chvostek's sign was positive, but Trousseau's sign was negative. The blood pressure was $130 / 70$ and the urine normal.

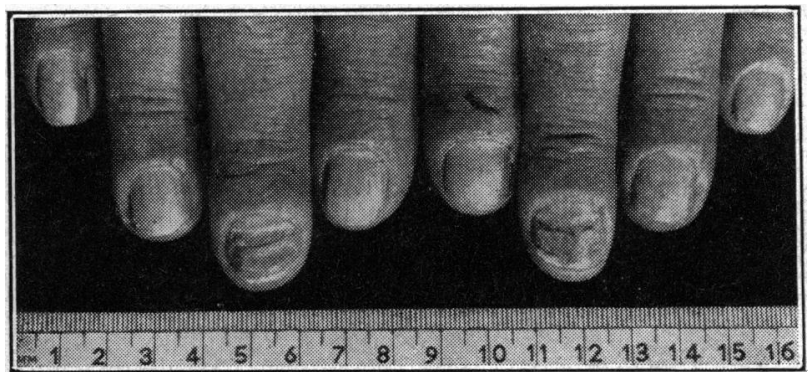

Fig. 4.-Case 2. Trophic changes in the finger-nails.

Investigations.-The serum calcium was $5.8 \mathrm{mg}$. and the phosphate $6.2 \mathrm{mg}$. per $100 \mathrm{ml}$. The Ellsworth-Howard test showed a normal response to parathyroid hormone (Fig. 1). $X$-ray films showed no calcification in the brain and the bone density was normal.

Treatment.-Dihydrotachysterol and calcium lactate were given, as shown in Fig. 5, the maintenance dose being $1 \mathrm{ml}$. and 75 gr. (5 g.) daily, respectively. The mental symptoms resolved soon after treatment was begun and the paraesthesiae disappeared. The nails have completely regrown (Fig. 6) and there is some evidence of regrowth of hair. There is no apparent change in his cataracts, and it has not so far been necessary to operate on them.

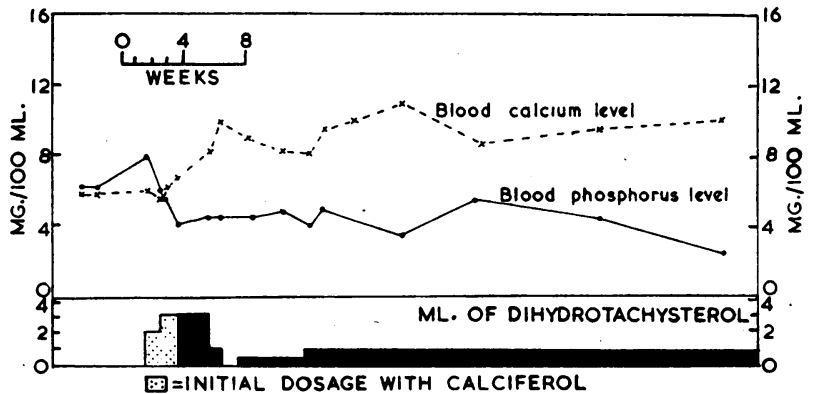

FIG. 5.-Case 2. Response of blood calcium and phosphate levels dihydrotachysterol dosage. $(50,000$ units of calciferol $=1 \mathrm{ml}$. of dihydrotachysterol.)

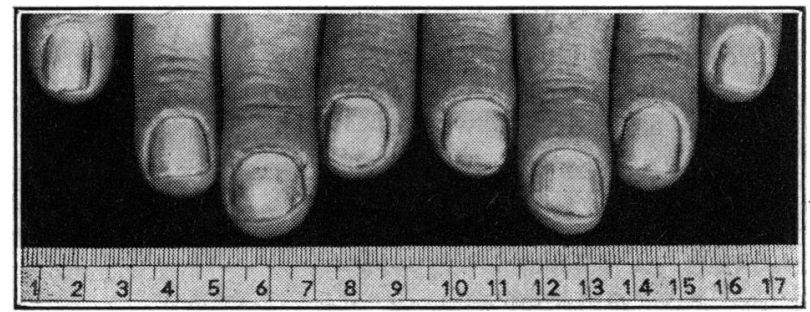

Fig. 6.-Finger-nails of Case 2 after six months' treatment with dihydrotachysterol.

\section{Case 3. Idiopathic Hypoparathyroidism}

This patient, a man aged 50 , had been seized with severe. cramps in the hands after an attack of "influenza" when aged 31. The cramps continued intermittently, being brought on particularly by his work as a boot-repairer. In March, 1933, two months after the onset of symptoms, he had an exceptionally severe attack, which involved the muscles of the face and throat, causing dyspnoea, and he was admitted to hospital. On admission Chvostek's and Trousseau's signs were strongly positive, and the serum calcium level was $5.4 \mathrm{mg}$. and the serum phosphate level $8 \mathrm{mg}$. per $100 \mathrm{ml}$. Within six hours after injections of calcium chloride and "para-thor-mone" the symptoms 
disappeared. He was discharged from hospital, free of symptoms, with a serum calcium level of $8.1 \mathrm{mg}$. per $100 \mathrm{ml}$. and taking calcium gluconate, 2 dr. $(8 \mathrm{~g}$.) thrice daily, and "ostelin," 3 minims $(0.18 \mathrm{ml}$.) thrice daily, and 2 pints (1.1 litres) of milk daily. On return to work, however, he continued to have cramps. These became more severe again and he was readmitted to hospital in December, 1933. At that time $x$-ray films showed normal bone density and there was no excess of fats in the faeces. He was treated with para-thor-mone 10 units weekly. Eight years after the onset of the tetany his vision began to fail. A cataract was removed from the left eye seven years later (in 1949), and another was removed from the right eye in December, 1951.

When first seen by us, on February 14, 1952, he was still having intermittent attacks of tetany, mainly after any infection or anxiety, or during the winter and spring. The spasms were painful and were accompanied by sweating. Hé had never had any epileptiform convulsions. He was not receiving any regular treatment, but was given injections of para-thor-mone during attacks of tetany, with complete relief. He had never had an operation on the thyroid gland.

On examination Chvostek's and Trousseau's signs were positive. There were no trophic changes in the skin, hair, or nails. The blood pressure was $130 / 80$ and the urine normal.

Investigations.-The serum calcium was $6 \mathrm{mg}$. and the serum phosphate $4 \mathrm{mg}$. per $100 \mathrm{ml}$. He had, however, received an injection of para-thor-mone a fortnight previously, and after a further 10 days without treatment the calcium fell to $5.5 \mathrm{mg}$. and the phosphate rose to $5.4 \mathrm{mg}$. per $100 \mathrm{ml}$. The serum alkaline phosphatase was 7.5 units per $100 \mathrm{ml}$. The Ellsworth-Howard test gave a normal response to parathyroid hormone (Fig. 1). $X$-ray films showed normal bone density and no evidence of calcification in the brain.

Treatment.-The serum calcium level has been raised to $8.8 \mathrm{mg}$. per $100 \mathrm{ml}$. by treatment with dihydrotachysterol, and the serum phosphate figure is now $3.6 \mathrm{mg}$. per $100 \mathrm{ml}$.

\section{Case 4. Pseudohypoparathyroidism}

This patient, a girl aged 18 , developed tetany after operation for an acute mastoid infection at the age of 6 . The symptoms were alleviated by "ostocalcium," but she continued to have mild tetany from time to time and the serum calcium level remained below normal. She had always been- undersized and mentally retarded. The menarche was at the age of 13 , since when she had menstruated normally. There was no relevant family history.

On examination she was dwarfed, thick-set, and somewhat obese. Her height was 55 in. $\left(140 \mathrm{~cm}\right.$.), span $53 \frac{1}{2}$ in. $\left(136 \mathrm{~cm}\right.$.), floor to pubis measurement $26 \frac{1}{2}$ in. $(67 \mathrm{~cm}$.), and pubis to vertex $28 \frac{1}{2}$ in. $(72 \mathrm{~cm}$.). Thus the limbs were a little short in comparison with the trunk. The hands and fingers were short and there was a characteristic roundness of the face (Fig. 7). $X$-ray films showed disproportionate shortening of the fourth and fifth metacarpals. The tibiae were slightly bowed, especially the left one. Secondary sexual development was normal, except for a slight degree of hirsutism. There were no defects in the skin, hair, and nails, and no lens opacities, but the teeth were poorly formed. Chvostek's and Trousseau's signs were positive. The blood pressure was $110 / 65$ and the urine normal.

Investigations. - The serum calcium was $6 \mathrm{mg}$., phosphate $6.8 \mathrm{mg}$., and alkaline phosphatase 2.7 units per $100 \mathrm{ml}$. The Sulkowitch test showed no calcium in the urine and quantitative estimation showed only $12 \mathrm{mg}$. per 24 hours. The Ellsworth-Howard test showed almost complete resistance to parathyroid hormone (Fig. 1). $X$-ray films showed patches of calcification in the basal ganglia of the brain. The bone density was normal. Epiphysial closure was well advanced for her age. Small patches of calcification were seen in the soft tissues of the limbs, some of them being deposited along the course of the blood vessels. The first premolars of the lower jaw and the first molars of both jaws were unerupted and none of the second molars showed proper root formation. Renal function was impaired; the urine could be diluted to 1002 and concentrated to 1020 , but the maximal urea concentration was only $1.08 \%$. Intravenous pyelography was normal.

Treatment.-Dihydrotachysterol, 1 ml. (1.25 mg.), was given three times d a ily. Calcium was detectable in the urine after one week, and within three weeks the s e r u m calcium level had risen to $11.6 \mathrm{mg}$. per 100 ml. The symptoms and signs of tetany disappeared, and the patient has remained well, with normal serum calcium and phosphate levels, on a maintenance dose of $0.5 \mathrm{ml}$. of dihydrotachysterol daily.

\section{Case 5. Post-operative Hypoparathyroidism}

A woman aged 37 had had two operations for hyperthyroidism at the ages of 31 and 35 . On the second occasion a total thyroidectomy was performed, as the surgeon was suspicious that the goitre might be malignant. After operation she lost her voice, and in the course of five months became myxoedematous. She responded to treatment with thyroid, but then began to have epileptiform convulsions with asphyxial symptoms. She developed a marked laryngeal stridor, due to abductor paralysis of both vocal cords, presumably from injury to the recurrent laryngeal nerves. A tracheotomy was performed, but this failed to relieve the asphyxial attacks. The epileptiform convulsions were not relieved by phenytoin sodium, $1 \frac{1}{2}$ gr. $(0.1 \mathrm{~g}$.) twice daily, and one year after the second operation she also began to have paraesthesiae in the neck and in the right arm and leg. At this time, while her blood pressure was being recorded, it was noticed that she showed a positive Trousseau's sign, and the serum calcium level was found to be $7.2 \mathrm{mg}$. (phosphate $4.2 \mathrm{mg}$.) per $100 \mathrm{ml}$.

Calcium lactate, 75 gr. (5 g.) and calciferol, 6,000 units daily, failed to alter the serum calcium level, and after a week she was given $9 \mathrm{ml}$. (11.25 mg.) of dihydrotachysterol daily. The serum calcium level rose to $10 \mathrm{mg}$. per $100 \mathrm{ml}$. after nine days and the fits ceased to occur. For the past four years she has been maintained on a dose of 6,000 units of calciferol daily, together with 75 gr. $(5$ g.) of calcium lactate. It has not been possible to dispense with the tracheotomy, and it is therefore clear that the laryngeal palsy was not a result of the hypocalcaemia. It is of interest that both she and her siblings had convulsions in infancy, which suggests that her threshold for convulsions is low.

\section{Case 6. Post-operative Hypoparathyroidism}

A married woman aged 46 underwent three operations for a non-toxic goitre between the ages of 15 and 17 . She apparently had no symptoms until five years later, when she began to have generalized convulsions. These were thought to be epileptic and were treated as such for a number of years. Some 14 years later it was recognized that she was suffering from chronic tetany. At that time sho showed bilateral cataracts, and the serum calcium level was $6.5 \mathrm{mg}$. per $100 \mathrm{ml}$; the serum phosphate level was 
not estimated. She was treated with a high calcium intake, hydrochloric acid, and ammonium chloride, with only partial relief. Two years later she was given calciferol, 100,000 units daily, with remarkable improvement. The cataract in the right eye was removed at the age of 44 . A year later she began to develop menopausal symptoms, accompanied by emotional instability and a tendency to overbreathe, thus precipitating further symptoms of tetany.

When first seen by us she had been taking vitamin $D$, 100,000 units daily, for eight years, but was still having tetany. Chvostek's sign was weakly positive, and Trousseau's sign was strongly positive, being accompanied by emotional disturbance and overbreathing. The hair of her head was generally sparse. The blood pressure was $170 / 110$ and the urine normal. The serum calcium was $7.1 \mathrm{mg}$., phosphate $4.5 \mathrm{mg}$., and alkaline phosphatase 9.5 units per $100 \mathrm{ml}$. The electrocardiogram showed left axis deviation with low voltage $T_{1}$, inverted $T_{2}$ and $T_{3}$, and depression of the ST segment. The Q-T interval was prolonged. $X$-ray films showed marked calcification in the basal ganglia and in the region of the cerebellum. The bone density was normal. The Ellsworth-Howard test showed a poor response to the injection of 40 units of para-thor-mone (Fig. 1).

Dihydrotachysterol was substituted for calciferol, and the symptoms and the serum calcium level were controlled by a maintenance dose of 0.66 to $1 \mathrm{ml}$. daily. Three months later the cataract in the left eye was successfully removed, but a month later still, after a respiratory infection, the symptoms of tetany and epilepsy relapsed to their original state. Neither the symptoms nor the serum calcium level could be controlled by as much as $4 \mathrm{ml}$. of dihydrotachysterol daily, and treatment with calciferol was resumed instead. The symptoms were well controlled by a dose of 200,000 units daily, and four successive normal serum calcium figures were obtained within a fortnight under inpatient conditions. Five days after discharge from the ward she developed anorexia, followed by thirst, polyuria, an unpleasant taste in the mouth, weakness of the limbs, dyspnoea, and vomiting, and she was readmitted five days later in a confused state, with muscular atony and a serum calcium level of $15.9 \mathrm{mg}$. per $100 \mathrm{ml}$. The calciferol was discontinued, but she became maniacal and deluded, and had to be transferred to a mental ward. She subsequently developed a hemiparesis, and the blood urea rose to $72 \mathrm{mg}$. per $100 \mathrm{ml}$. Both the mental symptoms and the hemiparesis cleared up within 10 days, and the serum calcium level fell to normal after a further four weeks.

\section{Case 7. Post-operative Hypoparathyroidism}

A married woman aged 23 underwent thyroidectomy for hyperthyroidism at the age of 21 . Four days after operation she developed tetany, which was relieved by injections of calcium gluconate and dihydrotachysterol. Treatment with dihydrotachysterol was continued only intermittently, in view of difficulty in obtaining supplies. Fifteen months later she became pregnant, and continued to term in spite of the fact that she received no calcium or dihydrotachysterol during pregnancy. There was, however, a return of the attacks of tetany during labour. Lactation was terminated after two months on account of a breast abscess. When inadequately treated she was inclined to emotional instability and hyperventilation, with exacerbation of her tetany. She was investigated when not under the influence of treatment, and showed positive Chvostek's and Trousseau's signs, a serum calcium level of $6.1 \mathrm{mg}$. and a phosphate level of $4.9 \mathrm{mg}$. per $100 \mathrm{ml}$., and only a trace of calcium in the urine. The Ellsworth-Howard test showed a normal response to parathyroid hormone (Fig. 1). There were no defects in the skin, hair, or nails, and no opacities in the lenses on examination with a slit-lamp.

Her symptoms were controlled, and a normal serum calcium level was maintained, on a dose of $1 \mathrm{ml}$. of dihydrotachysterol daily.

\section{Mode of Presentation}

Tetany.-Three of our cases presented with this symptom (Cases 3, 4, and 7). Carpopedal spasms also occurred in Cases 1,5 , and 6 , but they were overshadowed by other manifestations. In Case 2 the only symptoms of tetany which could be elicital were mild paraesthesiae and cramps. The symptoms may indeed vary from trivial paraesthesiae to severe generalized spasms. Sometimes these involve the respiratory muscles, and, rarely, the diaphragm is affected, with fatal results. Shelling (1935) describes other occasional manifestations of tetany, such as strabismus, nystagmus, abnormalities of the pupils, dysphagia, dysarthria, symptoms of pyloric or intestinal obstruction, bronchial spasm, retention or incontinence of urine, peripheral oedema, Raynaud's phenomenon, tachycardia, cardiac irregularities, or even sudden cardiac arrest. Boothby et al. (1931) describe weakness and fatigability of the muscles, and Lachmann (1941) describes intermittent pareses in the limbs in one case. Infantile convulsions may occasionally be due to hypoparathyroidism, which may be physiological in the neonatal period or may represent the onset of idiopathic hypoparathyroidism (Bakwin, 1939).

Epilepsy.-Cases 5 and 6 presented with typical major seizures, and were treated for some time as cases of idiopathic epilepsy. In Case 6 the fits did not begin until five years after thyroidectomy, which made the diagnosis more elusive. Approximately $40 \%$ of the cases of idiopathic hypoparathyroidism recorded in the literature have presented with epilepsy, and many cases have escaped recognition as a result of this. Either major or minor seizures may occur. They are not necessarily associated with frank symptoms of tetany, and, when they are, their onset is often independent, but they usually cease when the serum calcium level is restored to normal. The electroencephalogram may show typical epileptic changes, and the abnormal waves tend to disappear with correction of the serum calcium level, but the record does not necessarily become normal, suggesting either that these patients are latent epileptics or that irreversible cerebral changes have occurred (Kowallis, 1941 ; Taubenhaus and Engle, 1945 ; Mortell, 1946 ; Gotta and Odoriz, 1948). In Case 1 there were no true epileptic manifestations, but there was a history of seizures of a myoclonic pattern.

Ectodermal Lesions. - Case 2 showed patchy loss of hair, loss of the eyebrows and eyelashes, and deformity of the nails. More commonly, the hair of the head is generally sparse, and rarely there is complete alopecia. There may also be loss of pubic and axillary hair. In some cases the skin becomes dry, rough, and scaly. The nails and the mouth may become infected with moniliasis in idiopathic hypoparathyroidism (Thorpe and Handley, 1929 ; Sevringhaus, 1942 ; Sutphin et al., 1943 ; Talbot et al., 1943). Impetigo herpetiformis has also been described as an association with chronic tetany (Lachmann, 1941).

Cataracts.-Case 2 attended an eye hospital with cataracts in the first instance and was referred to a physician only because of the finding of a trace of reducing substance in the urine. Cataracts were also present in Cases 1, 3, and 6, and had to be extracted. They may occur in chronic hypocalcaemia from any cause (Albright and Reifenstein, 1948). Although some authors have claimed that those occurring in hypoparathyroidism have a distinct pattern and that they tend to develop in the subcapsular layer, O'Brien (1932) came to the conclusion that there was no characteristic morphology. Cataracts may develop in the absence of frank symptoms of tetany or when the symptoms have become much milder, either with or without treatment. They may develop rapidly, leading to blindness within a few months (Emerson et al., 1941).

It is clear that cases of hypoparathyroidism may present in various ways and that they may be referred in the first instance to various special departments. Thus Case 1 first came to a neurological clinic, and Case 2 to an eye hospital, and it is likely that other cases might be found in skin clinics. Though classical carpopedal spasms may easily be 
recognized, mild tetany may be mistaken for acroparaesthesiae, "neuritis," "fibrositis," "cramps," or " hysteria." More cases of hypoparathyroidism might come to light if the diagnosis were borne in mind in such cases, and in cases of epilepsy, in cases of cataract occurring in young persons, and in patients with trophic lesions in the skin, hair, and nails.

\section{Other Manifestations}

Changes in Teeth.-When parathyroid deficiency arises in childhood the enamel is often deficient and shows transverse ridges, and changes occur in the dentine. Sometimes there may be delay or failure of eruption. These changes do not occur when the disease arises in adult life, and decalcification never occurs (Albright and Strock, 1933).

Mental Changes.-Anxiety symptoms were prominent in Cases 6 and .7 , and there was a resulting tendency to hyperventilation, precipitating further attacks of tetany. Case 1 showed intellectual deterioration and emotional instability and incongruity, and Case 2 showed moroseness, irritability, impairment of memory, and loss of interest in his appearance. Frank psychoses of manic-depressive and delusional types have been described (Barr et al., 1938 ; Eaton and Haines, 1939; Greene and Swanson, 1941; Scarlett and Houghtling, 1944). These mental changes usually resolve within a few weeks after the serum calcium is restored to normal, which suggests that they are the direct result of hypocalcaemia. Mental retardation has also been recorded in a number of cases of idiopathic hypoparathyroidism arising in childhood.

Papilloedema occurs occasionally. It subsides when the serum calcium level is restored to normal (Albrecht, 1923 ; Shelling and Goodman, 1934 ; Barr et al., 1938 ; Hurxthal, 1942 ; Sutphin et al., 1943 ; Mortell, 1946 ; Berezin and Stein, 1948). The combination of papilloedema and epilepsy may suggest a cerebral tumour.

Physical Development.-In a number of cases arising in childhood the patients have been undersized. The height has been recorded in the literature in 10 cases in which the patient has reached the age of 18 . The heights ranged from 57 to $67 \mathrm{in}$. (145 to $170 \mathrm{~cm}$.), average $61 \frac{3}{4}$ in. $(156 \mathrm{~cm}$.). In some cases puberty has been delayed and secondary sexual characters have been underdeveloped.

Other Endocrine Disorders.-These are seldom found. Hypothyroidism occasionally occurs in post-operative cases (as in Case 4); it has also been described in two idiopathic cases (Himsworth and Maizels, 1940 ; Lachmann, 1941). Addison's disease has been associated with idiopathic hypoparathyroidism in three cases (Sutphin et al., 1943 ; Talbot et al., 1943 ; Leonard, 1946). In Leonard's case necropsy showed atrophy of the adrenal glands as well as absence of the parathyroids ; in the case of Sutphin et al. there was tuberculous infection.

Hypoparathyroidism has not been recorded in panhypo: pituitarism, and there is no good evidence that a pituitary parathyrotrophic factor exists. This subject is reviewed by Collip (1940), Törnblom (1949), and Engfeldt (1950).

\section{Diagnosis}

Blood Chemistry.-The serum calcium figure is reduced and the serum inorganic phosphorus level is raised. The normal range for the serum phosphate level is given by Albright and Reifenstein (1948) as $3.2 \mathrm{mg}$. per $100 \mathrm{ml}$. \pm 0.5 but in our laboratories it is from 2.5 to $5 \mathrm{mg}$. per $100 \mathrm{ml}$. Drake, Albright, et al. (1939) regard a raised serum phosphate level as an essential diagnostic criterion. This distinguishes hypoparathyroidism from other low-calcium disorders, such as rickets, osteomalacia, and steatorrhoea, in which the blood is unsaturated with calcium and phosphorus and both levels tend to be low. The only other condition in which a low serum calcium level and a high serum phosphorus level are found is chronic renal disease; this should therefore be excluded. In Case 1 the serum phosphorus level was never higher than $4.5 \mathrm{mg}$. per $100 \mathrm{ml}$.; this figure is raised by Albright and Reifenstein's standards, though it falls within our normal range.

Radiological Findings.-Calcification was present in the basal ganglia in three of our cases (Cases 1, 4, and 6). In Cases 4 and 6 it was punctate, but in Case 1 it was arranged in radiating striations (see Fig. 2). The radiological aspects of Cases 1 and 3 have already been reported (Medill, 1951), and the subject is reviewed by Camp (1947), Siglin, Eaton, Camp, and Haines (1947), and Foley (1951). The bone density is normal or increased. It was increased in Case 1, but was normal in the others. Rarefaction does not occur as a primary feature of hypoparathyroidism; it was reported in one of Emerson, Walsh, and Howard's cases (1941) and in one of Lachmann's cases (1941), but in both of these it was probably due to post-menopausal osteoporosis. The metabolic and radiological changes can best be explained on the basis of the theory of Albright and his colleagues that the primary action of parathyroid hormone is to increase the excretion of phosphorus in the urine, leading to a fall in the serum phosphate level and a compensatory rise in the serum calcium level. It follows that in hypoparathyroidism the initial change will be a rise in the serum phosphate level, followed by a compensatory fall in the serum calcium level. Since the blood is fully saturated with calcium phosphate, a rise in the phosphate concentration, together with continued absorption from the intestine, will lead to a tendency to supersaturation of the blood, with an increase in deposition of bone salt and an increase in bone density (Albright and Reifenstein, 1948). The cerebral calcification may be due to the same mechanism, but it is not clear why the brain is affected and other soft tissues are not.

Electrocardiographic Changes.-The characteristic change of hypocalcaemia is seen-namely, prolongation of the Q-T interval.

Electroencephalographic Changes.-There may be : (a) slow waves of 2 to 5 cycles a second (as in Case 1), usually in series of three or four waves, but sometimes in stretches of up to 10 seconds; (b) typical epileptic changes, with groups of slow waves and spikes; (c) a continuous generalized disturbance of rhythm ; or (d) a normal record (Gotta and Odoriz, 1948).

\section{Pseudo-hypoparathyroidism}

This consists of three independent genetic defects. (1) There is a disturbance of the peripheral action of parathyroid hormone, producing effects exactly similar to those of true hypoparathyroidism, except that the injection of parathyroid hormone usually fails to increase the excretion of phosphate in the urine (see Fig. 1). The parathyroid glands are shown to be normal or hyperplastic on biopsy. (2) There is a dyschondroplasia, resulting in a short stature and in shortening of various bones, particularly the metacarpals and metatarsals. (3) There is a tendency for the subcutaneous tissues to become calcified and to form bone. The appearance of these patients is characteristic. They are short and thick-set; the face is rounded (see Fig. 6) and they are often mentally retarded. All these features are well shown by Case 4 . The suggestion that the condition is due to a genetic disturbance is confirmed by its occurrence on two occasions in a pair of twins, and in another case in a mother and child (Elrick et al., 1950).

The distinction from true hypoparathyroidism is to a large extent academic, as the treatment is the same, but it is of considerable general interest, since it shows that an endocrine disorder may result not only from failure of secretion of a hormone but also from an abnormal peripheral response to it.

\section{Treatment}

Para-thor-mone is of very limited value, since acute cases following operation are more rapidly controlled by administration of calcium salts, and in chronic cases the hormone has four disadvantages : (1) it is expensive, (2) it has to be given by injection, (3) it is apt to give rise to local 
reactions, and (4) it leads to antibody-formation and therefore begins to lose its effect after a few weeks (Albright and Ellsworth, 1929).

Either calciferol (vitamin $\mathbf{D}_{2}$ ) or dihydrotachysterol should be used. These substances differ in chemical structure only in the saturation of a double bond. Whereas parathyroid hormone increases the excretion of phosphate in the urine but has no effect upon calcium absorption, calciferol acts principally upon calcium absorption, and only to a less extent upon phosphate excretion. Dihydrotachysterol, on the other hand, more closely resembles parathyroid hormone in its action, in that it acts primarily upon excretion of phosphate and only to a less extent upon absorption of calcium (Albright et al., 1938). There is also evidence that both calciferol and dihydrotachysterol have a direct action upon bone, leading to resorption and mobilization of calcium (Selye, 1932).

Dihydrotachysterol is usually given in doses of $3 \mathrm{ml}$. (3.75 mg.) daily initially, the dose being reduced to 0.5 or $1 \mathrm{ml}$. (0.625 to $1.25 \mathrm{mg}$.) daily for maintenance treatment. Calciferol usually has to be given in doses of 100,000 to 400,000 units daily (Sevringhaus and St. John, 1943) or occasionally 500,000 units (Himsworth and Maizels, 1940).

McLean (1941) states that the toxic effects of vitamin D have been overemphasized, and that many of the effects reported by earlier workers were due to the high toxisterol content of the original preparations. The dangers are by no means negligible, however, as Anning et al. (1948) and Howard and Meyer (1948) have pointed out. Anning et al. found toxic symptoms in $19 \%$ of 200 patients who were receiving 100,000 to 150,000 units of calciferol daily for treatment of various skin dieases. Howard and Meyer describe toxic effects in 11 cases but only one of these was suffering from hypoparathyroidism. The symptoms of intoxication consist of thirst, anorexia, vomiting, tiredness, malaise, nausea, headache, constipation, abdominal pain, polyuria, intolerance of noise, loss of weight, excitability, photophobia, rhinorrhoea, generalized pruritus, and, occasionally, drowsiness and coma, psychic disturbances, impaired memory, paraesthesiae, muscular pains and atony, and amblyopia. Howard and Meyer report calcium deposits beneath the conjunctival basement membranes, as seen with the slit-lamp, in 9 of 11 cases, and albuminuria in seven cases. All their cases showed impairment of renal function, with blood non-protein-nitrogen levels of 46 to $106 \mathrm{mg}$. per $100 \mathrm{ml}$. Psychotic changes as severe as those occurring in Case 6 do not appear to have been reported previously. It seems that the risk of toxic effects is smaller in cases of hypoparathyroidism, and in fact few such cases have been reported. But Howard and Meyer's case and our Case 6 show that the risk exists and that the consequences may be serious.

It is probable that toxic symptoms are due to an individual idiosyncrasy or to impaired renal function. In Case 6 they resulted from a dose of 200,000 units daily, and in Howard and Meyer's case of hypoparathyroidism on a dose of 300,000 units daily, whereas many other patients have received much higher doses without untoward effects. Both in Case 6 and in Howard and Meyer's case the symptoms occurred within three weeks of starting calciferol treatment, though our Case 6 had previously received a prolonged course of 100,000 units daily, and had been thought to have developed mild intoxication some years previously.

If toxic symptoms appear the drug must be discontinued immediately, fluids must be given copiously, and the calcium intake must be reduced to a minimum. Howard and Meyer found that the serum calcium level remained raised for two to four months, and in one case for as long as 20 months, during which time the blood urea level remained slightly raised and renal function remained impaired. Under such conditions there is, of course, a risk of widespread soft-tissue calcification. In our Case 5 the serum calcium level returned to normal within four weeks.

Similar toxic effects have been observed by some workers with dihydrotachysterol, but these have not been of serious import; no fatal case has been reported so far as we are aware, and no evidence has been obtained of chronic damage, even when the serum calcium level has been raised temporarily as high as $15 \mathrm{mg}$. per $100 \mathrm{ml}$. (McLean, 1941). Dihydrotachysterol is probably less likely to give rise to hypercalcaemia than is calciferol, since it does not predominantly influence calcium absorption.

Summarizing, dihydrotachysterol is preferable to calciferol on theoretical grounds, in that it more closely resembles parathyroid hormone in its action. In practice there seems to be little difference between them so far as their effect upon the clinical and biochemical picture is concerned. But, assuming that an average maintenance dose of dihydrotachysterol is $0.5 \mathrm{ml}$. daily, and that this is equivalent to 100,000 units of calciferol daily, the expense of treatment amounts to approximately $£ 1$ a month in the case of dihydrotachysterol, as against approximately $1 \mathrm{~s}$. a month in the case of calciferol. On the other hand, calciferol is probably more likely to produce hypercalcaemia, since it acts primarily upon calcium absorption. Occasional cases show resistance to dihydrotachysterol (Holtz, 1933), and cases of pseudo-hypoparathyroidism may be relatively resistant to dihydrotachysterol as well as to parathyroid hormone (Albright et al., 1942).

We have not found it necessary to give calcium salts as well, and, as dosage has to be readjusted repeatedly, it would appear to be easier to deal with only one variable than with two. Nor have we paid any attention to the diet, as no patient is likely to maintain a strict intake of calcium and phosphorus, and it does not seem to be necessary to control it. Milk should, however, not be taken in excess, for its phosphorus content is high (Albright and Reifenstein, 1948).

Albright and Reifenstein state that treatment can be controlled adequately by testing the urine for calcium, with Sulkowitch reagent. We have not found the Sulkowitch test to be reliable in practice. In Case 6 only a moderate reaction was obtained, even though the patient was in a state of acute hypercalcaemia, and on other occasions we have found subnormal calcium levels when the Sulkowitch reaction was optimal. Sevringhaus and St. John (1943) and Jordan and Kelsall (1951) have also found the test to be not completely reliable. In our experience, it is necessary to control treatment by means of repeated estimations of the serum calcium level. The chief value of the Sulkowitch test is that it can be performed regularly by the patient himself, and that a strongly positive or negative reaction should warn him that his treatment requires immediate readjustment. It is important that the test-tubes should be cleaned with distilled water, as tap-water usually contains considerable amounts of calcium.

Dosage may have to be increased during pregnancy, but a few cases improve at this time, as in Case 7 and in Scarlett and Houghtling's case (1944), and some cases quoted by Lachmann (1941). The dose may also have to be increased during periods of physical and mental strain, during infections, and after operations.

In practice we have found that stabilization is not nearly as easy as might appear at first sight, and that the dosage repeatedly needs to be adjusted. The principles of treatment are in fact very similar to those involved in the treatment of diabetes mellitus.

The aim should be not only to control symptoms but to maintain a persistently normal level of serum calcium, in the attempt to avoid such serious complications as cataracts, mental changes, and calcification in the brain.

\section{Summary}

Three cases of idiopathic hypoparathyroidism, three post-operative cases, and one case of pseudo-hypoparathyroidism are described.

The cases usually present with tetany, the symptoms of which are very variable. Epilepsy is also a common presenting symptom. Some cases may present with 
cataracts or with ectodermal defects. Other manifestations include defects in the teeth, psychoneurotic or psychotic disturbances, papilloedenia, and physical and mental retardation.

The serum calcium level is reduced and the serum phosphate level is raised.

$X$-ray films often show calcification in the brain, especially in the basal ganglia, and normal or increased density of the bones.

The electrocardiogram shows a prolonged $\mathrm{Q}-\mathrm{T}$ interval and the electroencephalogram shows abnormal slow waves or epileptic changes.

Pseudo-hypoparathyroidism is due to abnormal resistance to parathyroid hormone and presents exactly similar features, together with a dyschondroplasia, resulting in a short stature and shortening of the metacarpal and metatarsal bones, and a tendency to metaplastic bone formation in the soft tissues.

Treatment is by means of dihydrotachysterol or calciferol. Theoretically, the former is preferable, in so far as it more closely resembles parathyroid hormone in its action; but in practice there is little to choose between them. Dihydrotachysterol has the disadvantage that it is considerably more expensive, while calciferol is probably more apt to give rise to hypercalcaemia.

Though idiopathic hypoparathyroidism and pseudohypoparathyroidism are generally regarded as rare disorders, it is likely that more cases would come to light if the diagnosis were borne in mind in cases with obscure paraesthesiae and pains and cramps in the limbs, and in cases of epilepsy, of cataract in young persons, and of defects in the ectodermal tissues.

We are grateful to Dr. P. M. F. Bishop, Dr. M. J. McArdle, and Dr. W. N. Mann for permission to publish their cases and for their help and advice. Professor R. H. S. Thompson advised and encouraged us from the start, and the biochemical investigations were carried out in his and in Dr. W. H. H. Merivale's laboratories at Guy's Hospital and in Dr. E. N. Allott's laboratory at Lewisham General Hospital. We are also indebted to Dr. W. A. Oliver, who referred the case of pseudo-hypoparathyroidism, to Dr. A. Bookless and Dr. D. Gullick, who referred two of the post-operative cases, and to the medical illustration and photographic departments of Guy's Hospital, Lewisham General Hospital, and the Institute of Ophthalmology.

Addendum.-Since this article was submitted for publication we have found it necessary to increase the doses of dihydrotachysterol (A.T.10) considerably above the amounts indicated in the text. Thus Case 4 now requires $6 \mathrm{ml}$. daily, and Case $74 \mathrm{ml}$. daily, of the material at present available in this country, in order to maintain a normal serum calcium level. Case 3 has required $3 \mathrm{ml}$. throughout. We are in close consultation with the manufacturers, who are investigating this discrepancy.

\section{REFERENCES}

Albrecht, K. (1923). Mschr. Psychiat. Neurol, 55, 55.

Albright, F., Bloomberg, E., Drake, T., and Sulkowitch, H. W. (1938)

J. clin. Invest.. 17, 317 .

30, 922. Clinworth, R. (1929). J. clinvest., 7, 183

and Reifenstein. E. C. (1948). The Parathyroid Glands and Metabolic Bone Disease. Baillière, Tindall and Cox, London.

Bone Disease. Baillière, Tindall and Cox, London.

Anning S. T. Dawson, J., Dolby, D. E., and Ingram, J. T. (1948). Quart. J. Med., 17, 203.

J. Med., 17, 203.

Bakwin, H. (1939). J. Pediat., 14, 1 Sanders, T. E. (1938). Trans. Ass. Amer. Phys., 53, 227.

Amer. Phys., 53, Stein, J. D. (1948), J. Pediat., 33, 346.

Berezin, S. M. A. and de Mowbray, R R (1951).'Proc. roy. Soc. Med. 44, 952 .

Bomberton, J. de J. (1931). Amer. J. med. Sci., 181, 81 .

Camp. J. D. (1947). Radiology, 49, 568.

Camp. . D. (1947). Rann. Surg. 100284

Cattell, R. B. (1940). A Amer med. Ass. $115,2073$.

Collip, J. B. (1940). J. Amer. Aned. A intern. Med 12 , 1751 intern. Med., 12, 1751
Elrick, H., Albright, F., Barter, F. C., Forbes, A. P., and Reeves, J. D. (1950). Acta endocr., Kbh., 5, 199.

Emerson, K., Walsh, F. B., and Howard, J. E (1941). Ann. intern. Med., 14, 1256

Engfeldt, B. (1950). Acta endocr., Kbh., Suppl. 6

Foley, J. (1951). J. Neurol. Neurosurg. Psychiat., 14, 253.

Gotta, H., and Odoriz, J. B. (1948). J. clin. Endocr., 8, 674

Greene, J. A., and Swanson, L. W. (1941). Ann. intern. Med., 14, 1233.

Himsworth, H. P., and Maizels, M. (1940). Lancet, 1, 959.

Holtz, F. (1933)."Arch. klin. Chir., 177, 32.

Howard, J. E., and Meyer, R. J. (1948). J. clin. Endocr., 8, 895

Humphreys, H. F. (1939). Proc. roy. Soc. Med., 32, 633.

Hurxthal, L. M. (1942). Lahey Clin. Bull., 2, 238.

Jordan, A., and Kelsall, A. R. (1951). Arch. intern. Med., 87, 242

Kowallis, G. F. (1941). Proc. Mayo Clin., 16, 129.

Lachmann, A. (1941). Acta med. scand., Suppl. 121

Leonard, M. F. (1946). J. clin. Endocr., 6, 493.

McLean, F. C. (1941). J. Amer. med. Ass., 117, 609.

Medill, E. V. (1951). Brit. J. Radiol., 24, 685.

Morteli, E. J. (1946). J. clin. Endocr., 6., 266

O'Brien, C. S. (1932). Arch. Ophthal., 7, 71.

Scarlett, E. P., and Houghtling, W. J. (1944). Canad. med. Ass. J., 50. 351.

Selye, H. (1932). Endocrinology, 16, 547.

Sevringhaus, E. L. (1942).Amer. J. med. Sci., 203, 726

and St. John, R. (1943). J. clin. Endocr., 3, 635.

Shelling, D. H. (1935). The Parathyroids in Health and Disease. Mosby, St. Louis.

- and Goodman, M. J. (1934). J. Amer. med. Ass., 102, 669

S:glin, I. S., Eaton, L. M., Camp, J. D., and Haines, S. F. (1947). J. clin. Endocr., 7, 433.

Sutphin, A., Albright, F., and McCune, D. J. (1943). J. clin. Endocr., 3,

Talbot, N. B., Butler, A. M., and MacLachlan, E. A. (1943). Amer. J. Dis. Child., 69, 1267.

Taubenhaus, M., and Engle, H. M. (1945). J. clin. Endocr., 5. 147.

Thorpe, E. S., and Handley, H. E. (1929). Amer. J. Dis. Child.. 38, 328. Törnblom, N. (1949). Acta endocr. Kbh., Suppi. 4.

\section{THE RECENT TRENDS OF INFECTIOUS DISEASES IN CHILDHOOD}

BY

W. J. MARTIN, D.Sc., Ph.D.

(From the Medical Research Council's Statistical Research Unit, London School of Hygiene and Tropical Medicine)

Since the inception of the National Health Service Act in 1948 the level of the notifications of three common infectious diseases of childhood-scarlet fever, whooping-cough, and measles-has been above that of the immediately preceding years. During the first quarter of 1951 the weekly notifications of both measles and whooping-cough reached the highest point since these diseases were made notifiable, and an even larger incidence of measles has been recorded in the first quarter of 1953. Diphtheria, on the other hand, has declined consistently and rapidly, and the average weekly notifications during the first quarter of 1953 were only 20 , compared with 900 for the first quarters of 1940 and 1941. The number of notifications and the deaths per 1,000 notifications for these four diseases, for the years 1940 to 1952 , are shown in Table I. The incidence of measles, scarlet fever, and whooping-cough rose in 1948, and it may well be thought that the recent high level of these diseases is due only to the operation of the National Health Service, because medical advice is more often sought regarding mild cases. It is to be noted, however, that the incidence of all three was unusually large for the first six months of 1949that is, preceding the operation of the Service-as can be seen from Figs. 1, 2, and 3 .

Table I shows that the fall in the fatality rates, which had been apparent since 1942, was accentuated in 1948 for measles and whooping-cough. The fatality rates for these diseases were about half of those in the preceding year. The obvious explanation for the large drop in fatality is that more mild cases were being notified. Scarlet fever did not show a large fall in the fatality rate, and the decrease was no larger than would have 